\title{
LA APLICACIÓN DEL PRIMER PROTOCOLO ADICIONAL DEL CONVENIO EUROPEO DE DERECHOS HUMANOS A LAS PRESTACIONES SOCIALES ¿FRENO PARA LAS REFORMAS DE SEGURIDAD SOCIAL?
}

\author{
THE APPLICATION OF THE FIRST ADDITIONAL PROTOCOL \\ OF THE EUROPEAN HUMAN RIGHTS CONVENTION \\ TO SOCIAL BENEFITS, BRAKE FOR SOCIAL SECURITY \\ REFORMS?
}

\author{
Cristina SÁnchez-Rodas NaVARro \\ Catedrática de Derecho del Trabajo y Seguridad Social \\ Universidad de Sevilla \\ Código ORCID: 0000-0001-9780-7860
}

Recibido: 08.07.2018 / Aceptado: 11.07.2018

DOI: https://doi.org/10.20318/cdt.2018.4394

\begin{abstract}
Resumen: Aunque el derecho a la Seguridad Social aparece regulado en numerosos Tratados internacionales, ni el Convenio Europeo de Derechos Humanos ni sus Protocolos Adicionales la contemplan. Y, sin embargo, son numerosas las sentencias del Tribunal Europeo de Derechos Humanos que tienen por objeto la tutela del derecho a percibir prestaciones sociales contributivas, no contributivas y de naturaleza mixta. El elemento en común que tienen esas sentencias - que se analizan en el primer bloque- es que el Tribunal parte de la premisa de que el derecho a prestaciones sociales es un derecho de propiedad tutelable al amparo del artículo primero del Primer Protocolo Adicional al Convenio Europeo de Derechos Humanos. En base a dicho precepto España ya ha sido condenada en dos ocasiones en materia de pensiones de Seguridad Social. Esta jurisprudencia podría convertirse, además, en un límite a la potestad legislativa de los Estados que, como España, introdujeron importantes recortes en materia de pensiones en los años más duros de la última crisis económica y financiera mundial.

En el segundo bloque se estudia el impacto de dicha jurisprudencia del Tribunal Europeo de Derechos Humanos en el Tribunal de Justicia de la Unión Europea, del que la cuestión prejudicial Florescu es, hoy por hoy, la única exponente. Por último se analiza la jurisprudencia de nuestro Tribunal Constitucional que viene manteniendo el criterio que en materia de prestaciones sociales no existe un derecho de propiedad, sino una expectativa de derecho no indemnizable.
\end{abstract}

Palabras clave: Derecho de propiedad, prestaciones contributivas, prestaciones no contributivas, Primer Protocolo Adicional al Convenio Europeo de Derechos Humanos.

Abstract: Although the right to Social Security is regulated in numerous international Treaties, neither the European Convention on Human Rights nor its Additional Protocols contemplate it. Nevertheless, there are numerous judgments of the European Court of Human Rights that have for object the protection of the right to receive social contributory, non-contributory and of a mixed nature benefits. The common element in these judgments - which are analyzed in the first block - is that the Court starts from the premise that the right to social benefits is a property right that can be protected under the first article of the First Additional Protocol to the European Convention. of Human Rights. Based on this precept, Spain has already been sentenced twice in cases related to Social Security pensions. This jurispru- 
dence could also become a limit to the legislative power of States that, like Spain, introduced important pension cuts in the harshest years of the last global economic and financial crisis.

The second block examines the impact of this jurisprudence of the European Court of Human Rights in the Court of Justice of the European Union, of which the preliminary question Florescu is, at present, the only exponent. Finally, we analyze the jurisprudence of our Constitutional Court that has maintained the criterion that in the field of social benefits there is no property right, but an expectation of non-compensable right.

Keywords: Property rights, contributory benefits, non-contributory benefits, First Additional Protocol to the European Convention on Human Rights.

Sumario: I. El Estado del Bienestar, la Seguridad Social y la "Nueva propiedad".II. De la regulación del Derecho a la Seguridad Social en el Derecho Internacional y en el Derecho de la Unión Europea a la anomia del Convenio Europeo de Derechos Humanos.1.Derecho Internacional. 2. Derecho de la Unión Europea 3. Convenio Europeo de Derechos Humanos III. El artículo primero del primer protocolo adicional del Convenio Europeo de Derechos Humanos 1. Autonomía del concepto de propiedad. 2. El Derecho a prestaciones sociales contributivas y no contributivas como Derecho patrimonial en la jurisprudencia del Tribunal Europeo de Derechos Humanos. A) Una ficticia dicotomía basada en las vías de financiación. B) Gaygusuz c. Austria: subsidio por desempleo mixto.C) Wessels-Beergervoet c. Países Bajos: Pensión de jubilación no contributiva . D) Willis c. Reino Unido: subsidio de viudedad no contributiva.E) Anzinas c. Chipre: El acceso a la función pública como derecho de posesión de la futura pensión.3. Sentencias condenatorias contra España en materia de pensiones fundadas en el artículo primero del primer protocolo adicional.A) Muñoz Díaz: Summun ius Summa Iniuria. B)Manzanas Martín. 4. Reformas Legislativas de pensiones contrarias al primer protocolo adicional .A) Kjartan Asmundsson c. Islandia.B) Bélané Nagy c. Hungría.C) Baczúr c. Hungría .5. Reforma de la revalorización de pensiones en España y Convenio Europeo de Derechos Humanos .IV. El Derecho a pensión como Derecho de propiedad en la Carta de Derechos Fundamentales de la Unión Europea. 1. El impacto de la jurisprudencia del Tribunal Europeo de Derechos Humanos en la jurisprudencia del Tribunal de Justicia de la Unión Europea .2. La no adhesión de la Unión Europea al Convenio Europeo de Derechos Humanos.3. La cuestión prejudicial Florescu.A) La Reforma de pensiones en Rumanía como respuesta a la crisis. B) Sobre la vulneración del artículo 17 de la Carta de los Derechos fundamentales de la Unión Europea V. El primer protocolo adicional del Convenio Europeo de Derechos Humanos, ¿Canon hermenéutico para interpelar el derecho a prestaciones sociales en España?.1. El artículo 10.2 CE.A) Sobre el alcance del concepto de Derechos fundamentales a los efectos del artículo 10.2 CE.B) Las prestaciones sociales como Derecho de propiedad, ¿Derecho fundamental?.VI. Las prestaciones sociales, ¿Derecho de propiedad para el Tribunal Constitucional?.VII. Conclusiones.

\section{El estado del bienestar, la Seguridad Social y la "Nueva propiedad" ${ }^{1}$}

1. Con la expresión "Estado del Bienestar" se alude al modelo de Estado en el que las necesidades básicas de los ciudadanos aspiran a ser cubiertas por los Poderes Públicos mediante prestaciones tanto en metálico como en especie. Su expansión tuvo lugar tras la Segunda Guerra Mundial debido a las especiales circunstancias políticas y sociales de ese período histórico y, de otro lado, coincidiendo con la etapa de crecimiento económico experimentado a partir de la segunda mitad del S.XX. Aunque todos los Estados de la UE pueden calificarse de Estados del Bienestar, no existe un modelo uniforme, pudiendo distinguirse el conservador (Francia, Austria, Italia y Alemania); el liberal (Estados Unidos, Canadá y Australia); y el socialdemócrata o Nórdico (surge en Suecia y se expande en toda la península Escandinava)².

2. Entre los pilares del Estado del Bienestar la Seguridad Social ocupa, sin duda alguna, un lugar de preeminencia.

\footnotetext{
${ }^{1}$ Esta publicación se enmarca dentro de los trabajos de investigación desarrollados en el Proyecto I+D "La Seguridad Social Internacional y Comunitaria" (DER 2017-83040-C4-3-R) financiado por el MINECO.

2 M.C. Gómez Isaza, La Historia del Estado Social de Derecho, Universidad de Antioquía, 2006, pp.92-93.
} 
3. El auge de la función del Estado como distribuidor de recursos a través de prestaciones sociales y proveedor del Bienestar de la sociedad llevó a Charles A. Reich a sostener en un célebre artículo titulado "The New Property"3 que las prestaciones sociales habían pasado a configurarse como unos nuevos derechos de propiedad como consecuencia de las nuevas relaciones entre los beneficiarios de la asistencia estatal y el Estado.

4. El impacto de esta teoría no sólo fue teórico, sino que la Corte Suprema americana la hizo suya en el caso Golberg v. Kelly en el que admitió que no se podía privar unilateralmente de ayudas sociales a los ciudadanos, sino que habían de tener derecho a una audiencia imparcial. No se llegó, sin embargo, a reconocer a los beneficiarios de la asistencia estatal la misma protección jurídica que la legislación desde antiguo ha dispensado al derecho de propiedad privada ${ }^{4}$.

5. Pero con el transcurso del tiempo los postulados de Reich no sólo no han caído en el olvido sin que van ganando terreno: en Europa en 1980 el Tribunal Constitucional alemán fue pionero -en base al principio de la confianza legítima (Vertrauenschutz)- en reconocer que la protección dispensada al derecho de propiedad podía comprender ciertas prestaciones de Seguridad Social destinadas a garantizar la existencia de la persona asegurada cuando se tratase de prestaciones financiadas a través de cotizaciones imputables al beneficiario, de manera que existiera una equivalencia global entre la prestación y las cotizaciones abonadas, ya sea a título individual o por un tercero a favor del asegurado ${ }^{5}$.

6. El segundo Tribunal Constitucional en seguir esta tesis fue el húngaro en $1995^{6}$, que admitió que las prestaciones de Seguridad Social contributivas son tutelables como derecho de propiedad. No así los subsidios asistenciales respecto a los cuales sólo puede alegarse una expectativa de Derecho.

7. Aunque en ambos países se puso inicialmente el acento en el dato fáctico del pago de previas cotizaciones como causa para dispensar protección jurídica, posteriormente el énfasis pasó a centrarse en el carácter instrumental de las prestaciones sociales para garantizar un cierto nivel de libertad a los beneficiarios. En concreto, la tutela de las prestaciones sociales como derecho patrimonial entroncaría con la función social de la propiedad.

8. A partir de la última década del pasado Siglo también la jurisprudencia del Tribunal Europeo de Derechos Humanos ha hecho suya la tesis de que el derecho a prestaciones sociales se incardina en la tutela que el Convenio Europeo de Derechos Humanos dispensa al derecho de propiedad.

\section{De la regulación del derecho a la Seguridad Social en el Derecho Internacional y en el Derecho de la Unión Europea a la anomia del Convenio Europeo de Derechos Humanos}

\section{Derecho Internacional}

9. Son numerosos los Tratados y Convenios internacionales en los que podemos encontrar referencias explícitas al término Seguridad Social, entre los que pueden mencionarse a título ejemplificativo:

I. el artículo 5 de la Carta del Atlántico (1941).

II. El artículo 22 de la Declaración Universal de los Derechos Humanos (1948).

III. El Convenio ${ }^{\circ} 102$ de la OIT de Norma mínima de Seguridad Social (1952).

IV. El artículo 12 de Carta Social Europea.

\footnotetext{
${ }^{3}$ C. A. Reich, "The New Property", The Yale Law Journal, nº5, 1964.

${ }^{4}$ D.A. Super, “A New New Property”, Columbia Law Review, Vol. 113, pp. 1868-1878.

${ }^{5}$ T. Maunz y R. ZipPelius, Deutsches Staatsrecht, C.H. Beck'sche Verlagsbuchhandlung. München, 1991, pp.94 y 95.

${ }^{6}$ P.Sonnevend,Eigentumsschutz und Sozialversicherung, Veröffentlichungen des Max-Planck-Instituts für ausländisches öffentliches Recht und Völkerrecht,Band 185.
} 
10. En otras ocasiones no es Seguridad Social el término utilizado por los instrumentos internacionales sino Protección Social, concepto al que se dota de un significado más extenso pues engloba no sólo a las prestaciones de Seguridad Social en sentido estricto, sino también "todas aquellas acciones y medidas de carácter fundamentalmente público que tiene por objeto la protección de los ciudadanos frente a situaciones de necesidad"'. Precisamente ésta es la terminología empleada por la Recomendación n 202 de 2012 de la OIT "Relativa a los Pisos Nacionales de Protección Social”.

\section{Derecho de la Unión Europea}

11. El Derecho de la Unión Europea procede de una fuente autónoma, constituida por los Tratados y se caracteriza por su primacía sobre los Derechos de los Estados y por el efecto directo de toda una serie de disposiciones aplicables a sus nacionales y a los propios Estados, tal y como se afirma en el Dictamen 2/13 del TJUE de 18.12.2014.

\section{Derecho Originario}

12. El artículo 34 de la Carta de los Derechos Fundamentales de la Unión Europea lleva por título "Seguridad Social y Ayuda Social". Pero su redacción dista de ser diáfana pues no permite establecer una nítida frontera entre Seguridad Social, servicios sociales y ventajas sociales.

13. De conformidad con el artículo 6.1 del Tratado de la Unión Europea, la Carta de los Derechos Fundamentales de la Unión Europea "tendrá el mismo valor jurídico que los Tratados".

14. Por su parte, en el articulado del TFUE encontramos referencias tanto a la Seguridad Social individualmente considerada (p.e., artículos 48 y 156) como a la Seguridad Social y a la protección social conjuntamente reguladas (p.e., artículos 21.3 y 153.1.c).

\section{Derecho Derivado}

15. A nivel de Derecho derivado la disposición más relevante, el Reglamento 883/2004 de coordinación de sistemas de Seguridad Social, tampoco contiene una definición de Seguridad Social ni de Asistencia Social, lo que ha generado una abundante jurisprudencia del TJUE sobre el deslinde entre prestaciones no contributivas de Seguridad Social (coordinadas) y de Asistencia Social (excluidas de la coordinación).

16. Para complicar aún más el debate prestaciones que conforme al Reglamento $883 / 2004$ son prestaciones de Seguridad Social han sido calificadas como ventajas sociales por el Tribunal de Justicia de la Unión al aplicar el artículo 7.2 del Reglamento 492/2011. Este último precepto garantiza a los trabajadores migrantes ciudadanos de Estados en los que se aplica el Derecho de la UE las mismas ventajas sociales y fiscales que a los trabajadores nacionales.

\footnotetext{
${ }^{7}$ F. Elorza Guerrero, “Constitución Española y Protección Social”,en VV.AA. Constitución Española y Relaciones Laborales Ante el Actual Escenario Social y Económico, Consejo Andaluz de Relaciones Laborales, Sevilla, 2013, p.150.

8 “1. La Unión reconoce y respeta el derecho de acceso a las prestaciones de seguridad social y a los servicios sociales que garantizan una protección en casos como la maternidad, la enfermedad, los accidentes laborales, la dependencia o la vejez, así como en caso de pérdida de empleo, según las modalidades establecidas por el Derecho comunitario y las legislaciones y prácticas nacionales.

2. Toda persona que resida y se desplace legalmente dentro de la Unión tiene derecho a las prestaciones de seguridad social y a las ventajas sociales con arreglo al Derecho comunitario y a las legislaciones y prácticas nacionales.

3. Con el fin de combatir la exclusión social y la pobreza, la Unión reconoce y respeta el derecho a una ayuda social y a una ayuda de vivienda para garantizar una existencia digna a todos aquellos que no dispongan de recursos suficientes, según las modalidades establecidas por el Derecho comunitario y las legislaciones y prácticas nacionales".

${ }^{9}$ STJUE de 11 de Septiembre de 2007, caso Hendrix, asunto 287/05, Rec. 2007 I-06909 (ECLI:EU:C:2007:494), entre otras.
} 


\section{Convenio Europeo de Derechos Humanos}

17. Ni en el Convenio Europeo de Derechos Humanos ni en sus Protocolos Adicionales existe referencia alguna a la Seguridad Social ni a la Protección Social.

18. $\mathrm{Y}$, sin embargo, son numerosas las sentencias del Tribunal Europeo de Derechos Humanos (TEDH) que tienen por objeto la tutela del derecho a la percepción de prestaciones sociales, tanto contributivas, no contributivas y de naturaleza mixta atendiendo a sus vías de financiación.

19. ¿Cómo es ello posible si el requisito sine qua non para que el TEDH pueda conocer de demandas en las que se cuestione la regulación nacional es que se invoque la infracción de los derechos regulados en el propio CEDH o en sus Protocolos Adicionales?.

20. El elemento en común que tienen todas estas sentencias es que el TEDH parte de la premisa de que el derecho a prestaciones sociales es un derecho de propiedad tutelable al amparo del artículo primero del Primer Protocolo Adicional al Convenio Europeo de Derechos Humanos.

\section{El artículo primero del primer protocolo adicional del Convenio Europeo de Derechos Humanos}

21. Este precepto, que resulta vinculante para los Estados firmantes y es directamente invocable por los sujetos incluidos dentro del ámbito de aplicación personal del CEDH, proclama que: "toda persona física o moral tiene derecho al respeto de sus bienes. Nadie podrá ser privado de su propiedad más que por causa de utilidad pública y en las condiciones previstas por la Ley y los principios generales del Derecho Internacional. Las disposiciones precedentes se entienden sin perjuicio del derecho que poseen los Estados de poner en vigor las Leyes que juzguen necesarias para la reglamentación del uso de los bienes de acuerdo con el interés general o para garantizar el pago de los impuestos u otras contribuciones o de las multas".

22. Las versiones oficiales del Convenio Europeo de Derechos Humanos son las redactadas en lengua inglesa y francesa. La lectura del artículo 1 del Primer Protocolo Adicional en ambos idiomas nos lleva a concluir que no coinciden literalmente: en un caso se utiliza el término "droit de propiété" -derecho de propiedad- mientras que la otra utiliza la expresión "his right to peaceful enjoyment of his possessions" -su derecho al disfrute pacífico de sus bienes-. Sin embargo estas diferencias idiomáticas carecen de relevancia práctica al haber quedado zanjada la cuestión terminológica con la STEDH Marc$\mathrm{kx}$ de 13.6.1979 ${ }^{10}$.

\section{Autonomía del Concepto de propiedad}

23. Hay que resaltar que a los efectos del TEDH el concepto de propiedad tiene un alcance autónomo frente a los ordenamientos nacionales y "no se limita a la propiedad de los bienes físicos: determinados derechos e intereses que constituyen activos pueden considerarse también "derechos de propiedad" 11 .

24. De la jurisprudencia del TEDH se infiere que éste mantiene una interpretación extensiva del artículo 1 del Primer Protocolo Adicional en el que no sólo queda amparado el Derecho de propiedad en sentido estricto, sino también las expectativas de Derecho, tesis ya defendida tempranamente por Lemmes con apoyo en los casos Pine Valley Developments y Pressos Compañía Naviera ${ }^{12}$.

\footnotetext{
${ }^{10}$ F. Rey Martínez, "El Derecho de Propiedad Privada en el Derecho Europeo", Revista de Estudios Europeos, nº8, 1994, p. 53.

11 STEDH de 23 de febrero de 1995, caso Gasus Dosier y Fördertechnick, BJC 193 (1997), p.185.

${ }^{12}$ P. Lemmes;"The Gaygusuz Decision Situated in the Case Law of the European Court of Human Rights" en Stefan Van den Bogaert (Ed.), Social Security, Non-Discrimination and Property, Maklu. Antwerpen-Apeldoorn. The Netherlands, 1997, pp.26-28.
} 
25. Y, aunque el reconocimiento del derecho a la pensión tuviera carácter provisional, "un crédito también puede ser un bien en el sentido del artículo primero del Protocolo $\mathrm{N}^{\mathrm{o}} 1$, siempre y cuando esté suficientemente establecido para ser exigible" -STEDH de 14.12.1999 (Antonakopoulos c. Grecia)-.

26. Igualmente, es también jurisprudencia consolidada que, "desde el momento en que un Estado contratante establezca una normativa que prevea el pago automático de una prestación social debe considerarse que dicha normativa da lugar a un interés patrimonial que entra en el ámbito de aplicación del artículo 1 del Primer Protocolo Adicional respecto de las personas que cumplan sus requisitos" -SSTEDH de 6.11.2008 (Kokkinis c.Grecia) y de de 7.7.2011 (Stummer c. Austria), entre otras-.

\section{El derecho a prestaciones sociales contributivas y no contributivas como Derecho patrimonial en la jurisprudencia del Tribunal Europeo de Derechos Humanos}

\section{Una ficticia dicotomía basada en las vías de financiación}

27. Un tema clásico en la doctrina iuslaboralista nacional e internacional es la clasificación de las prestaciones sociales en contributivas (financiadas básicamente con cotizaciones sociales) y no contributivas (con cargo a tributos).

28. Por lo que a España se refiere, el artículo 109 del Texto Refundido de la Ley General de Seguridad Social clasifica el elenco de prestaciones sociales dispensadas por el sistema español de Seguridad Social utilizando esa misma dicotomía. Aunque, de hecho, la clasificación española no es en absoluta rigurosa ya que hay prestaciones que no se financian con cotizaciones y sin embargo se clasifican de prestaciones contributivas (p.e. el complemento de pensión contributiva por maternidad -artículo 60 TRLGSS-). Asimismo, se clasifican como prestaciones contributivas las prestaciones por desempleo cuando la realidad es que se nutren tanto de impuestos como de cotizaciones stricto sensu.

29. A mayor abundamiento, la doctrina mayoritaria -tanto fisca $1^{13}$ como laboralista ${ }^{14}$ - reconocen la naturaleza tributaria de la cotización. Tesis de la que se hace eco el Tribunal Constitucional ${ }^{15}$.

30. En la esfera del Derecho de la Unión Europea, el Reglamento 883/2004 de coordinación de sistemas de Seguridad Social, incluye dentro de su ámbito de aplicación material tanto a las prestaciones contributivas y no contributivas de Seguridad Social, así como a las prestaciones especiales en metálico no contributivas. Pero el citado Reglamento 883/2004 no contiene una definición de lo que haya de entenderse por prestación "contributiva" o "no contributiva". En todo caso las vías de financiación de una prestación resultan irrelevantes a la hora de incluirla o excluirla del ámbito material de los Reglamentos de coordinación: el Tribunal de Justicia de la Unión Europea ha establecido que no se excluyen de su ámbito de aplicación las prestaciones independientes de cotización previa ${ }^{16}$. Además, es jurisprudencia consolidada que bajo ciertos requisitos es posible que lo que a nivel de legislación interna se califican de impuestos sean cotizaciones sociales a los efectos del Derecho de la Unión Europea ${ }^{17}$.

31. En cualquier caso, como comprobaremos inmediatamente, las vías de financiación de las prestaciones sociales resultan intranscendentes para el TEDH a la hora de determinar si el derecho a las mismas se incardina dentro del ámbito de aplicación material del artículo primero del Primer Protocolo Adicional.

${ }^{13}$ J.A. Martínez Azuar, "La Naturaleza Tributaria de las Cotizaciones Sociales", Civitas, Revista Española de Derecho Financiero, $\mathrm{n}^{\circ}$ 96, 1997, p.526.

${ }^{14}$ M.R. Alarcón Caracuel, La Seguridad Social en España, Aranzadi, Pamplona, 1999, p.70.

${ }^{15}$ STC 39/1992, de 30 de marzo (ECLI:ES:TC:1992:39): “es innegable que el sistema de protección social se ha ido separando progresivamente del esquema contributivo y acercándose de forma cada vez más al concepto de tributación. Cfr. También SSTC189/1987 de 24 de noviembre (ECLI:ES:TC:1987:189), 127/1987 de 4 de febrero (ECLI:ES:TC:1987:127), 65/1987 de 21 de mayo (ECLI:ES:TC:1987:65) y 103/1983 de 22 de noviembre (ECLI:ES:TC:1983:103).

${ }^{16}$ Entre otras, SSTJUE de 31 de marzo de 1977, asunto 79/76, caso Fossi, Rec. I-00667 (ECLI:EU:C:1977:59); de 24 de febrero de 1987, asuntos acumulados -379/85 a 381/85 y 93/86, caso Giletti, Rec. 1987 00955 (ECLI:EU:C:1987:98).

${ }^{17}$ STJUE de 10 de mayo 2017, caso Lobkowicz, asunto 690/15, (ECLI:EU:C:2017:35). 


\section{A) Gaygusuz c. Austria: Subsidio por desempleo mixto}

32. Aunque la tesis de incluir el derecho a prestaciones sociales en el ámbito de aplicación material del Primer Protocolo Adicional no fue descartada por la extinta Comisión Europea de Derechos Humanos en los asuntos X.v. Holanda, de 20.7.1971 y Müller v. Austria, de 16.12.1974' ${ }^{18}$, habrá que esperar al 19.9.1996 para que, por primera vez, el TEDH califique a una prestación de Seguridad Social como derecho patrimonial en el sentido del artículo 1 del Primer Protocolo Adicional.

33. En el caso Gaygusuz la prestación en litigio era un subsidio austriaco por desempleo ("asistencia de emergencia") destinado a garantizar un ingreso mínimo de supervivencia a aquellos trabajadores que hubieran agotado la prestación por desempleo, de cuyo ámbito de aplicación personal se excluía a los nacionales de Terceros Estados. Puesto que este subsidio se reconocía a quienes hubieran sido beneficiarios previamente de una prestación contributiva por desempleo, existía un vínculo indirecto entre cotizaciones previas y el subsidio (aunque éste último no se financiara mediante cotizaciones de los trabajadores y/o sus empresarios). El demandante, de nacionalidad turca, había trabajado legalmente en Austria.

34. El Tribunal sostuvo por unanimidad que el derecho a una prestación destinada a personas sin recursos suficientes y financiados tanto con aportaciones estatales como de los trabajadores, está comprendida dentro del ámbito de aplicación material del artículo 1 del Primer Protocolo Adicional del $\mathrm{CEDH}$, no resultando justificables las diferencias de trato para su reconocimiento fundadas en la nacionalidad del solicitante. Siendo a estos efectos irrelevantes las vías de financiación de la prestación (impuestos o cotizaciones), o que su concesión esté subordinada a una prueba de insuficiencia de recursos.

\section{B) Wessels-Beergervoet c. Países Bajos: Pensión de jubilación no contributiva}

35. La prestación en litigio (AOW) es una pensión holandesa financiada mediante un porcentaje sobre el impuesto sobre la renta. Su cuantía es uniforme y se abona a quienes cumplen 65 años. Para tener derecho a la prestación completa es preciso acreditar un período de 50 años de seguro. Existe una reducción del 2\% por cada año que la persona no ha residido en los Países Bajos.

36. En esta sentencia, de 4.6.2002, la demandante invocó que la reducción de su pensión de jubilación constituía una discriminación por razón de sexo contraria al artículo 14 del CEDH, en conexión con el artículo $1^{\circ}$ del Protocolo $\mathrm{n}^{\circ} 1$, puesto que en el momento en que sucedieron los hechos, una mujer casada sólo estaba asegurada por la AOW cuando su marido estaba asegurado también.

37. Frente a la tesis de la demandante, el Gobierno alegaba que los beneficios de los planes de seguros sociales caracterizados por el principio de la solidaridad social no podían ser considerados como "bienes" en el sentido del artículo 1 del Protocolo $\mathrm{n}^{\mathrm{o}} 1$, ya que, a diferencia de los sistemas en los que el nivel de beneficios está supeditado a las aportaciones, un sistema basado en la solidaridad social distribuye los recursos disponibles por igual entre todos los interesados.

38. A mayor abundamiento, el Gobierno destacaba el decisivo dato de que el derecho a los beneficios de la AOW no depende de si se han hecho, o no, aportaciones. Por tanto, el grupo de contribuyentes es diferente del grupo de beneficiarios. Dada la ausencia de conexión entre contribución y derechos en virtud del plan AOW, el Gobierno consideraba que una pensión AOW no podía ser considerada incluida en el ámbito del artículo 1 del Protocolo $\mathrm{n}^{\circ} 1$.

\footnotetext{
${ }^{18}$ En el primero de ellos se afirmó que "el pago de contribuciones obligatorias a una caja de pensión puede crear, en ciertas circunstancias, un derecho de propiedad sobre una partida de estos fondos, y este derecho puede ser afectado por la manera en que los fondos son repartidos". En el segundo, la extinta CoEDH precisó que "la garantía del derecho a la pensión no da derecho a un montante determinado, salvo reducción sustancial, y que la renta derivada de un sistema de capitalización constituye un bien en el sentido del artículo 1 del Primer Protocolo Adicional".
} 
39. Frente a estos argumentos, el TEDH estimó que los derechos de la demandante a una pensión en virtud de la AOW podían ser contemplados como bienes en el sentido del artículo 1 del Protocolo $\mathrm{n}^{\circ} 1$.

40. Y, puesto que la única razón para la exclusión de la demandante del seguro de la AOW por un período de 19 años era el hecho de que estaba casada con un hombre que no estaba asegurado en virtud de lo dispuesto en la AOW porque trabajaba en el extranjero, el TEDH estima la demanda por considerar que la reducción aplicada a los beneficios de la AOW de la demandante estaba basada, exclusivamente, en el hecho de que era una mujer casada. Se constata, por tanto, la vulneración del artículo 14 del CEDH, en conexión con el artículo 1 del Protocolo ${ }^{\circ} 1$.

41. Con esta sentencia el TEDH reconoce que también las prestaciones financiadas íntegramente mediante tributos pueden ser calificadas como bienes susceptibles de protección al amparo del CEDH.

\section{C) Willis c. Reino Unido: subsidio de viudedad no contributiva}

42. El demandante, viudo, alegó haber sido víctima de una discriminación por razón de sexo por parte de la Seguridad Social británica, dada la negativa de las autoridades a abonarle las prestaciones de Seguridad Social a las que habría tenido derecho si hubiera sido una mujer en una situación similar.

43. Es interesante destacar cómo en el parágrafo 35 de esta sentencia de 6.11.2002 el TEDH afirma que no es necesario para el Tribunal plantearse en este caso la cuestión de si las prestaciones de la Seguridad Social deben ser contributivaspor naturaleza para que puedan constituir un "bien" (entrecomillado en el original) a efectos del artículo 1 del Protocolo $\mathrm{n}^{\mathrm{o}} 1$.

44. De lo que resulta que el Tribunal considera que el derecho a la paga de viudedad y al subsidio para madres viudas es un derecho económico suficiente para ser incluido en el ámbito de aplicación material del artículo 1 del Protocolo $\mathrm{n}^{\mathrm{o}} 1$.

45. Además, el Tribunal llega a la conclusión de que al demandante se le denegó el derecho a la paga de viudedad y al subsidio para madres viudas debido a una distinción contemplada por el artículo $14 \mathrm{CEDH}$, el sexo, que no está basada en ninguna justificación objetiva y razonable, por lo que estima la demanda.

\section{D) Anzinas c. Chipre: El acceso a la función pública como derecho de posesión de la pensión}

46. En la sentencia del TEDH de 20.6.2002, el Tribunal estimó la demanda del funcionario que, como parte de la sanción que le había sido impuesta por malversación de fondos públicos, fue privado del derecho a causar pensión de jubilación. El Tribunal acreditó la existencia de un incumplimiento del equilibrio exigido entre la protección del derecho de propiedad individual y los requerimientos de interés público.

47. La piedra angular de este caso vuelve a ser, una vez más, si una prestación no contributiva puede ser considerada como un bien a los efectos de su inclusión en el ámbito material de aplicación del artículo 1 del Protocolo ${ }^{\circ} 1$.

48. El gobierno chipriota estimaba que la pensión de jubilación no podía calificarse como posesión en el sentido del artículo 1 del Protocolo $n^{\circ} 1$. Y ello por cuanto que los funcionarios públicos no participan de un régimen contributivo de Seguridad Social que se nutra de las cotizaciones deducidas de sus retribuciones mensuales. Todas las prestaciones dispensadas por la República lo son a cargo de un Fondo Consolidado, conforme a lo previsto en la Constitución, que establece como criterio la obligación de la República de abonar una pensión específica, pero no alude a la existencia de un derecho al abono de las pensiones. 
49. El TEDH, partiendo de la premisa de que el derecho a una pensión, como tal, no está protegido por el CEDH, reitera, sin embargo, que de acuerdo con la doctrina de las instituciones del Convenio, el derecho a una pensión derivado de una actividad laboral previa puede, en ciertos casos, ser asimilado a un derecho de propiedad.

50. Tal sería el caso cuando se han satisfecho cotizaciones, pero también cuando un empleador, como el del litigio, garantiza con carácter general el pago de una pensión en base a condiciones que pueden ser consideradas como parte integrante de la prestación de servicios.

51. El TEDH alcanza el convencimiento de que el demandante cuando ingresó en la Función Pública chipriota, adquirió un derecho que constituye una posesión dentro del sentido del artículo 1 del Protocolo $\mathrm{n}^{\mathrm{o}} 1$, por lo que la privación de la pensión constituye una injerencia en su derecho de propiedad.

\section{Sentencias condenatorias contra España en materia de Pensiones fundadas en el artículo prime- ro del primer Protocolo adicional}

\section{A) Muñoz Díaz ${ }^{19}$ : Summun ius Summa Iniura}

52. El litigio analiza si es discriminatorio que la legislación española no atribuya efectos jurídicos al matrimonio por el "rito" gitano y en base a ello no tuviera la madre de los hijos del fallecido derecho a una pensión de viudedad.

53. En esta sentencia de 8.12.2009 el TEDH parte de la premisa que "desde el momento en que un Estado contratante adopta una normativa previendo el pago de una prestación social...se deberá considerar que esta normativa genera un interés patrimonial dependiente del ámbito de aplicación del artículo 1 del Protocolo $\mathrm{N}^{\mathrm{o}} 1$ ".

54. El TEDH rechazó por unanimidad que no reconocer efectos civiles a los "matrimonios" por el rito gitano sea constitutivo de una discriminación prohibida por el artículo 14.

55. Pero teniendo en cuenta las circunstancias específicas del caso, el Tribunal considera desproporcionado que el Estado español que emitió un libro de familia para la demandante y su familia, les reconoció el estatus de familia numerosa, les concedió a la interesada y a sus seis hijos asistencia sanitaria y percibió las cotizaciones de su marido gitano a la Seguridad Social durante más de diecinueve $\operatorname{años}^{20}$, no quiera ahora reconocer los efectos del matrimonio gitano en materia de pensión. Por ello el Tribunal declara por seis votos contra uno que España ha vulnerado el artículo 14 en conexión con el artículo 1 del Protocolo $N^{\circ} 1$.

56. La sentencia, sin embargo, merece ser objeto de rotunda crítica ya que España no debió ser nunca condenada en este caso por los siguientes motivos:

57. Para el TEDH la piedra angular para estimar la existencia de discriminación por no reconocer España pensión de viudedad a la Sra. Muñoz Díaz radica en el hecho de que ella y el padre de sus hijos estuvieran en posesión de un libro de familia y de familia numerosa de $1^{\text {a }}$ categoría. El TEDH invoca que, conforme al artículo 2 de la Ley 25/1971, "se considerará familia numerosa la que, reuniendo las demás condiciones que se señalan en esta Ley estén constituidas por: a) el cabeza de familia, su cónyuge, y cuatro o más hijos".

\footnotetext{
${ }^{19}$ M. Requena Casanova, "Tribunal Europeo de Derechos Humanos: Sentencia de 08.12.2009, Muñoz Díaz c. España,”, Revista de Derecho Comunitario Europeo, año ${ }^{\circ} 14, n^{\circ} 36,2010$, pp. 563-578.

${ }^{20}$ En el parágrafo 69, el TEDH hace suyo el último párrafo del voto particular a la STC 69/2007, y considera desproporcionado no reconocer pensión de viudedad cuando el Estado "ha percibido las cotizaciones de su marido gitano en la Seguridad Social durante más de 19 años".
} 
58. Pero esa normativa no era aplicable al caso: tras la entrada en vigor de la Constitución Española de 1978 se produce un cambio radical respecto a la situación jurídica de los hijos nacidos fuera del vínculo matrimonial: todos los progenitores -incluidos los no casados- podían obtener libro de familia. Pero no porque el legislador español equipare el matrimonio a las uniones more uxiore sino para acabar con la discriminación de que eran objeto los hijos no matrimoniales durante la etapa franquista cuya inscripción de nacimiento se llevaba a cabo en un libro distinto (libro de filiación) al de los hijos matrimoniales o "legítimos" (que se inscribían en el libro de familia.

59. Por tanto, tras la Constitución, tanto la obtención del libro de familia como del libro de familia numerosa dejó de estar condicionada a la existencia de un previo matrimonio. Y por eso le fueron expedidos libros de familia y de familia numerosa a la Sra. Muñoz Díaz y al padre de sus hijos en 1983 y 1986, respectivamente. Y en ninguno de ellos figura inscrita como esposa.

60. En diversas ocasiones el TEDH menciona que en una cartilla de la Seguridad Social la Sra. Muñoz Díaz sí aparecía como esposa. Pero el TEDH no transcribe en ninguno de los parágrafos de su sentencia el hecho recogido tanto en la STSJ de Madrid de 7.11.2002 como en la STC 69/2007 de que "en dicha cartilla junto al nombre de la Sra. Muñoz Díaz en la casilla parentesco hay una letra retocada que la sentencia (del Juzgado de lo Social) interpreta como esposa, siendo de significar en cualquier caso que lo que aparece es una letra inicial y que tal documento habría sido cumplimentado por el causante, cuya firma aparece en el anverso, no por la entidad gestora".

61. A mayor abundamiento, a partir de la Resolución de 29.12.1984 de la Secretaría General de la Seguridad Social se reconoce derecho a prestación sanitaria a las personas que, sin ser cónyuge, convivan con el titular del derecho, así como a sus hijos, siempre que demuestren que viven a sus expensas y que la convivencia ha tenido lugar de forma ininterrumpida como mínimo durante el año anterior a la solicitud de su reconocimiento como beneficiario.

62. En el parágrafo 69 el TEDH hace suyo el último párrafo del voto particular a la STC 69/2007 que considera desproporcionado no reconocer pensión de viudedad cuando el Estado "ha percibido las cotizaciones de su marido gitano en la Seguridad Social durante más de 19 años". Dejando al margen la incongruencia de que el TEDH califique como "marido" a quien no ha celebrado un matrimonio reconocido por la legislación nacional, respecto al argumento de vincular los años cotizados al derecho a una prestación de Seguridad Social hay que señalar que resulta insostenible puesto que los sistemas públicos de Seguridad Social no funcionan como un seguro privado. No hay por tanto correlación entre las cotizaciones que obligatoriamente han de realizar los sujetos legalmente obligados y las prestaciones que les puedan ser reconocidas. Es decir, que se puede cotizar y no tener derecho a una prestación contributiva y, a la inversa, lucrar una prestación contributiva sin cotizar. Como señaló HURTADO GONZÁLEZ "la cotización se configura como una obligación legal y autónoma de contribuir al sostenimiento de gastos públicos que no genera jurídicamente derecho patrimonial alguno, desconectada, por tanto, de aquél’²1.

\section{B) Manzanas Martín}

63. En la sentencia de 3.4.2012 el TEHD falla que España ha infringido los artículos 14 del Convenio Europeo de Derechos Humanos y el artículo 1 del Protocolo 1 del Convenio por la diferencia de trato de la normativa de pensiones aplicable a los sacerdotes católicos y a los pastores evangélicos, ya que a estos últimos no se les computaban los años anteriores a su integración al régimen de la Seguridad Social.

64. El Tribunal aplica el artículo primero del Primer Protocolo Adicional precepto que, sin embargo, "no supone un derecho a adquirir bienes, ni limita la libertad que tienen los Estados contratantes

${ }^{21}$ L.Hurtado GonzÁlez, "Derecho a la Protección de la Salud y Derecho a la Asistencia Sanitaria de la Seguridad Social", Tribuna Social. Revista de Seguridad Social y Laboral, nº. 78, 1997, pg. 30. 
para decidir si conviene o no poner en marcha un régimen de Seguridad Social o de elegir el tipo o el nivel de las prestaciones que deben ser acordadas".

65. Sigue en este fallo el TEDH su reiterada jurisprudencia según la cual se produce una discriminación cuando se trata de diferente manera a las personas que están en una situación comparable, salvo que exista una justificación objetiva y razonable. La "falta de justificación objetiva y razonable" significa que la distinción controvertida no persigue un "objetivo legítimo" o que no hay "una relación de proporcionalidad razonable entre los medios empleados y el objetivo perseguido".

66. El TEDH considera probado que las posibilidades ofrecidas a los sacerdotes católicos para que sean computados -a efectos de pensión de jubilación- los años anteriores a su integración al régimen de la Seguridad Social no se concedían a los pastores evangélicos en la legislación española.

67. Habida cuenta de las circunstancias del caso concluye el TEDH que esta diferencia normativa desfavorable constituye una diferencia de trato al demandante basada en la confesión religiosa. Y que no está justificada en relación al trato reservado a los sacerdotes católicos puesto que el demandante no dispone de ningún medio para que se tengan en cuenta, a efectos del cálculo de su pensión de jubilación, sus años de actividad pastoral como pastor evangélico antes de su integración en el régimen de la Seguridad Social.

\section{Reformas legislativas contrarias al primer protocolo adicional}

68. La premisa de partida es que el artículo 1 del Primer Protocolo Adicional no restringe la libertad de los Estados para regular sus prestaciones sociales ${ }^{22}$. Ni impone ninguna restricción a la libertad de los Estados contratantes para decidir instaurar, o no, un régimen de protección social o para escoger el tipo o el importe de las prestaciones que se pretende conceder en virtud de tal régimen.

69. En definitiva, la legislación en materia de Seguridad Social es competencia exclusiva de los Estados miembros, incluso cuando estos son miembros de la Unión Europea pues esa competencia no ha sido transferida por los Estados a las instituciones de la UE.

70. El TEDH, además, ha sostenido que "el hecho de que una persona haya entrado y forme parte de un sistema de Seguridad Social del Estado no significa necesariamente que ese sistema no se pueda cambiar, ya sea en cuanto a las condiciones de elegibilidad de pago o en cuanto a la cuantía de la prestación o pensión" -STEDH de 16.3.2010 (Carson y otros c. El Reino Unido)-.

71. Asimismo, el TEDH ha recurrido en algunas de sus sentencias a la doctrina del "margen de apreciación" de los Estados para inaplicar el Protocolo Adicional Primero ${ }^{23}$.

72. Pero el "margen de apreciación" y la competencia nacional para legislar en materia de Seguridad Social no implican, automáticamente, que resulten conformes al Primer Protocolo Adicional del CEDH todo tipo de reformas legislativas por parte de los Estados dirigida a reducir el gasto social. Prueba de ello son las sentencias que a continuación se traen a colación.

\section{A) Kjartan Asmundsson c. Islandia}

73. En esta sentencia de 12.10.2004, pese el amplio margen de apreciación que el TEDH reconoce a los Estados respecto de la legislación social, declaró vulnerado el artículo primero del Primer Protocolo Adicional al privarse a una persona totalmente y de forma sobrevenida de su derecho a una pensión de invalidez.

\footnotetext{
${ }^{22}$ STEDH de 26 de junio de 2014, caso Sujanov y Iltchenko c. Ucrania.

${ }^{23}$ L. Mola, "The margin of appreciation accorded to states in times of economic crisis:An analysis of the decision by the european committee of social rights and by the european court of human rights on national austerity measures", Revista Juridica de los Derechos Sociales, nº 1, 2015, p.182.
} 
74. Los hechos que dieron lugar al litigio pueden sintetizarse así: el demandante cobró pensión de invalidez derivada de contingencias profesionales desde 1978 hasta 1992, en que como consecuencia de una reforma legal que modificó el método de valoración de la discapacidad su pensión le fue suprimida tras un período transitorio de 5 años.

75. El TEDH constató que aunque las nuevas normas de pensiones se basaban en criterios objetivos, el que el demandante se viera privado por completo de la pensión de invalidez que en ese momento constituía no menos de un tercio de sus ingresos brutos mensuales y que había recibido durante casi 20 años, constituía una carga excesiva y desproporcionada y por tanto, vulneraba el artículo 1 del Primer Protocolo Adicional.

\section{B) Bélané Nagy c. Hungría}

76. La sentencia Bélané Nagy trae causa de la reforma de la legislación húngara que provocó que a la demandante, sin experimentar cambios en su estado de salud, se le suprimiera la pensión de incapacidad que cobraba en 2010. En 2012 entró en vigor una nueva ley que sustituyó la pensión de invalidez por un subsidio de invalidez, que también le fue denegado a la Sra. Bélané porque ni era beneficiara de la anterior pensión de invalidez ni acreditaba el período de carencia exigido.

77. La sentencia de 13.12.2016 enfatiza la importancia del principio impossibilium nulla obligatio est ya que la normativa vigente no puede exigir ex post acreditar un determinado período de carencia cuando ello resulta ya de imposible cumplimiento para la demandante.

78. El TEDH estimó que "el amplio margen de racionalización del que disponen los Estados respecto de sus sistemas de Seguridad Social no pueden justificar medidas carentes de toda proporcionalidad ni pueden comportar un sacrificio individual excesivo, ya que la Seguridad Social no deja de ser "la expresión de la solidaridad de la sociedad con sus miembros más vulnerables".

79. Por nueve votos contra ocho el TEDH falló que había habido vulneración del artículo 1 del Primer Protocolo Adicional. El ajustado margen de la votación ilustra a la perfección la tensión que provoca, por un lado, el Derecho de los Estados a reformar sus sistemas de Seguridad Social ${ }^{24}$, y los derechos de los beneficiarios de prestaciones sociales ante reformas legislativas restrictivas y fundadas en el principio de austeridad derivado de los efectos de la crisis económica y financiera mundial, de otro lado.

\section{C) Baczúr c. Hungría}

80. Respecto al tema de recorte de pensiones hay que traer a colación la sentencia del TEDH de 7.3.2017. El litigio traer causa de la reforma legislativa sobre el cálculo de la pensión de invalidez para personas con capacidad laboral reducida que provocó una reducción del importe de la pensión que el demandante venía percibiendo (de 510 euros mensuales se redujo a 140 mensuales). El demandante alegó que dado que su estado de salud no había mejorado había sido privado injustificadamente de su derecho de propiedad.

81. El TEDH admite que el sistema de Seguridad Social puede sufrir cambios, incluso en las condiciones de elegibilidad de pago o en la cantidad de las rentas o pensiones". Y también ha aceptado la posibilidad de modificaciones de la legislación de Seguridad Social como respuesta a cambios sociales.

82. En el caso Barzúc el TEDH toma en consideración que la prestación en litigio "constituye la expresión de la solidaridad de la sociedad con sus miembros más vulnerables". Para el Tribunal una

${ }^{24}$ A. Tsetoura, Property Protection as a Limit to Deteriorating Social Security Protection; European Journal of Social Security, vol. 15, 1, pp. 55-78. 
reducción de $2 / 3$ como la sufrida por el demandante ha infringido al contenido esencial de su derecho de pensión aunque el demandante -a diferencia de la Sra. Nagy- no fue completamente privado de sus derechos. Este elemento se agrava por el dato de que el demandante no tenía ninguna otra renta significativa con la que subsistir y pertenece al grupo vulnerable de personas con discapacidad. El TEDH considera que la aplicación de la legislación impugnada supuso una situación en la que no hubo una ponderación justa de los intereses en juego, incluso si la legislación tenía por objeto la protección del interés público racionalizando el régimen de las pensiones para personas con discapacidad, un problema de interés general en cuyo logro el Estado goza de un amplio margen de apreciación. Por todo ello el TEDH declara infringido el artículo 1 del Protocolo $\mathrm{N}^{\mathrm{o}} 1$ del Convenio Europeo de Derechos Humanos.

\section{Reforma de la revalorización de pensiones en España y Convenio Europeo de Derechos Humanos}

83. A partir de la Ley 24/1997, de Consolidación y Racionalización del Sistema de Seguridad Social, se estableció la revalorización automática de las pensiones en función del IPC previsto para ese año (artículos 48.1.1 TRLGSS 1/1994 y 27.1 párrafo primero del Texto Refundido de la Ley de Clases Pasivas del Estado -Real Decreto Legislativo 670/1987-). Y en caso de desviaciones del IPC previsto frente al real, se abonaba a los pensionistas una "paga" en el mes de abril compensatoria.

84. Debido precisamente "a la dureza y profundidad de la crisis económica" el artículo 4 del Real Decreto-ley 8/2010, por el que se adoptan Medidas Extraordinarias para la Reducción del Déficit Público, dejó en suspenso en 2011 la revalorización de las pensiones de la Seguridad Social en su modalidad contributiva.

85. En 2012 las pensiones se revalorizaron en un 1\% (artículo 5.1 del Real Decreto-ley 20/2011), aunque no se abonó a los pensionistas la diferencia entre el IPC real y el previsto de conformidad con el artículo segundo del Real Decreto-ley 28/2012, que asimismo dejó en suspenso la revalorización de las pensiones para el ejercicio de 2013. Las razones para tal proceder son, según su Exposición de Motivos, el elevado déficit del sistema de la Seguridad Social durante el ejercicio 2012 y la necesidad de cumplir con el objetivo del déficit público.

86. Contra el Real Decreto-ley $28 / 2012$ se interpuso recurso de inconstitucionalidad que fue desestimado por la STC 49/2015, de 5 de marzo, que falló que la suspensión de la revalorización conforme al IPC no infringía ningún precepto constitucional en base a la -discutible- aplicación al ámbito de la Seguridad Social de la doctrina de los derechos adquiridos en contraposición de las expectativas de derecho ${ }^{25}$. Esta última sentencia ha sido objeto de críticas porque podría abrir la puerta a "la discrecionalidad legislativa sobre la actualización de las pensiones según las circunstancias económicas y sociales en cada momento"26.

87. Con la entrada en vigor de la Ley $23 / 2013$, de 23 de diciembre reguladora del Factor de Sostenibilidad y del Índice de Revalorización del Sistema de Pensiones de la Seguridad Social, su artículo séptimo modificó la normativa sobre revalorización de pensiones contenida en el TRLGSS y en el Texto Refundido de Clases Pasivas, quedando establecida en un mínimo del 0,25\% y un máximo 0,5\%.

88. Es decir, que a partir de la Ley $23 / 2013$ el importe de las pensiones públicas queda desvinculado del Índice de Precios al Consumo ${ }^{27}$ ya se no toma como referente para la revalorización de las pen-

\footnotetext{
25 "De conformidad con una consolidada jurisprudencia constitucional, la retroactividad interdicta por el art. 9.3 CE resulta aplicable exclusivamente a los derechos individuales, entendidos éstos en los términos anteriormente expuestos, siempre y cuando se trate de derechos "consolidados, asumidos e integrados en el patrimonio del sujeto y no a los pendientes, futuros, condicionados y expectativas" (por todas, SSTC 99/1987, de 11 de junio (ECLI:ES:TC:1987:99), y 178/1989, de 2 de noviembre (ECLI:ES:TC:1989:178). Por consiguiente y para este Tribunal, solo cabrá apreciar que una norma es retroactiva, a los efectos del precitado art. 9.3 CE, cuando incide sobre "relaciones consagradas" y afecta a "situaciones agotadas".

${ }^{26}$ Eva María Blázquez Agudo,"Desde el Principio de Garantía de la Suficiencia de las Prestaciones a la Necesidad de Garantizar la Viabilidad del Sistema", Revista de Información Laboral, nº 5/2015, p.8.

${ }^{27}$ Esther Guerrero Vizuete, "La Deconstrucción del Sistema Público de Pensiones a través de la Ley 23/2013, de 23 diciembre. Reguladora del factor de Sostenibilidad”, Nueva Revista Española de Derecho del Trabajo, n 65/2014, pp. 98-108.
} 
siones el IPC sino el índice de revalorización de las pensiones cuya determinación dista mucho de ser de fácil comprensión ya que "se tienen en cuenta elementos tales como el número de pensionistas, la media de las pensiones de todos ellos, así como los ingresos y los gastos del sistema de Seguridad Social28".

89. Mientras el IPC fue negativo, la aplicación del índice de revalorización no conllevó contestación social. Sin embargo, y como era más que previsible, el nuevo mecanismo de revalorización de pensiones ha empezado a mermar el poder adquisitivo de los pensionistas y con ello auspiciado su empobrecimiento y las subsiguientes movilizaciones sociales de carácter reivindicativo.

90. De la fuerza de estos movimientos contestatarios con la política de pensiones del Gobierno y de la importancia del voto de los pensionistas que podrían inclinar la balanza en unas próximas elecciones da fe que el Gobierno haya tenido que dar finalmente marcha atrás en su política. Concretamente, en el Programa Nacional de Estabilidad presentado en abril 2018 se afirma que "las medidas de apoyo al colectivo de pensionistas también han sufrido alguna modificación durante la fase de tramitación parlamentaria. Se mantiene el escenario de incremento de las pensiones no contributivas y las pensiones mínimas, que se actualizarán en un 3\% en total, tal y como estaba previsto en el Proyecto de Presupuestos Generales del Estado para 2018 presentado ante el Congreso el pasado 3 de abril. Iniciada la negociación del Presupuesto en el Parlamento, se ha acordado que el resto de pensiones se incrementen un 1,6\% en total en 2018; y la base reguladora de las pensiones de viudedad en 4 puntos porcentuales. El incremento de las pensiones por encima de lo previsto en el Proyecto de Presupuestos Generales del Estado para 2018 supone un coste adicional de 1.522 millones de euros".

91. En 2018 el TEDH ha admitido a trámite una demanda contra España ${ }^{29}$ relativa a las reformas llevadas a cabo por la Ley 23/2013, de 23 de diciembre, reguladora del Factor de Sostenibilidad y del Índice de Revalorización del Sistema de Pensiones de la Seguridad Social. Se cuestiona, concretamente, si vulnera el derecho de propiedad de los pensionistas el que la nueva normativa desvincule el importe de las pensiones al Índice de Precios al Consumo, provocando con ello una pérdida del poder adquisitivo de los pensionistas.

92. Esta reforma acometida por el Gobierno español en el trienio 2011-2013 tiene su origen, en última instancia, en la crisis económica y financiera mundial iniciada en 2008. Y se enmarca dentro una política de contención del gasto público impuesta, por un lado, por el artículo 126 del TFUE y su Protocolo n ${ }^{\circ} 12$, "Sobre el Procedimiento Aplicable en Caso de Déficit Excesivo". Y de otro lado, por los compromisos internacionales asumidos mediante el Tratado de "Estabilidad, Coordinación y Gobernanza" -que provocaron la reforma del artículo 135 de nuestra Constitución- y del Tratado "Constitutivo del Mecanismo Europeo de Estabilidad".

\section{El Derecho de Propiedad en la Carta de Derechos fundamentales de la Unión Europea a la luz del primer protocolo adicional al Convenio Europeo de Derechos Humanos}

\section{El impacto de la jurisprudencia del Tribunal Europeo de Derechos Humanos en el Tribunal de Justicia de la Unión Europea}

93. El TJUE pasó de una inicial pasividad a una declarada defensa de los Derechos Fundamentales como principios generales del Derecho comunitario espoleado por la jurisprudencia de los Tribunales Constitucionales alemán e italiano ${ }^{30}$.

\footnotetext{
${ }^{28}$ Eva María Blázquez Agudo,"Desde el principio de Garantía de Suficiencia”, Op. Cit., pp.1-2.

${ }^{29}$ Presentada por el Colectivo Ronda en representación del activista y portavoz de Marea Pensionista, Domiciano Sandoval.

${ }^{30}$ De la jurisprudencia del Tribunal Constitucional alemán (Solange II y Soweit) e italiano (Granital y Fragd) se desprende que no se descarta completamente la posibilidad de que, llegado el caso, los Tribunales Constitucionales pudieran pronunciarse sobre la constitucionalidad de la normativa comunitaria si la protección del TJCE a los derechos fundamentales se mostrara insuficiente.
} 
94. A partir de la sentencia Nold ${ }^{31}$ el TJUE declarará que "los instrumentos internacionales referentes a la protección de los Derechos Humanos en los que han cooperado o a los que se han adherido los Estados miembros también pueden contener elementos que conviene tener en cuenta en el Derecho comunitario" $" 32$.

95. Jurisprudencia que se reitera en infinidad de sentencias posteriores y que permite afirmar con Louis $^{33}$ que "los Convenios Internacionales en materia de Derechos Humanos ${ }^{34}$ (Declaración universal, Convenio Europeo, pactos de las Naciones Unidas, Carta Social, etc...) serán fuentes en las que el Tribunal se inspirará" ${ }^{35}$. Llegando el Abogado General La Pergola ${ }^{36}$ a afimar que el Tribunal de Justicia tiene asignado "el papel de intérprete del CEDH por lo que respecta a las reglas que tengan relación con el Derecho comunitario".

96. Concretamente en relación con el CEDH, el TJUE viene declarando que no pueden admitirse en la Comunidad medidas incompatibles con el respeto de los Derechos Humanos ${ }^{37}$. A sensu contrario" no operará tal garantía cuando el derecho en cuestión no se encuentre amparado por el CEDH.

97. Ahora bien, las anteriores afirmaciones no deben llevar a la errónea conclusión de que entre ambos Tribunales existe una relación de jerarquía -lo que es falso- ni que el TJUE esté subordinado a la jurisprudencia del $\mathrm{TEDH}^{38}$.

98. Está fuera de toda duda que el derecho de propiedad se encuentra entre los Derechos Fundamentales que el ordenamiento jurídico comunitario garantiza ${ }^{39}$.

\section{La no adhesión de la UE al Convenio Europeo de Derechos Humanos}

99. Todos los Estados miembros de la UE han ratificado el CEDH.

100. El artículo 218.6 TFUE prevé la posibilidad de firmar un Acuerdo de Adhesión de la Unión al Convenio Europeo de Derechos Humanos. Sin embargo esta eventualidad ha de considerarse descartada tras el Dictamen 2/13 del TJUE de 18.12.2014 declarando la incompatibilidad del Proyecto de Acuerdo de Adhesión al Convenio Europeo de Derechos Humanos con el Derecho originario de la Unión.

101. En última instancia el escollo que hace imposible esta adhesión es la eventualidad de que la jurisprudencia del TEDH pudiera prevalecer sobre la interpretación del Derecho de la Unión efectuada por el TJUE. Así se infiere del Dictamen citado cuando afirma en su apartado 183 que "un acuerdo inter-

${ }^{31}$ STJCE de 14 de mayo de 1974, caso Nold, asunto 4/73, Rec. 197400491 (ECLI:EU:C:1975:114), p.508. Es de resaltar que la misma se dictó pocas semanas después de que Francia ratificara el CEDH.

32 J.A. Carrillo Salcedo, "La Protección de los Derechos Humanos en las Comunidades Europeas" en VV.AA, Tratado de Derecho Comunitario Europeo, Civitas, Madrid, 1986, p.21.

33 J.V. Lous, El Ordenamiento Jurídico Comunitario, $5^{\text {a }}$ edición, Luxemburgo, 1995, p.103.

${ }^{34}$ López-Medel resalta que "no es necesario para que el TJCE pueda referirse a uno de ellos, que el instrumento en cuestión haya sido ratificado por todos los estados miembros, bastando la cooperación o adhesión". Cfr. M. LóPEz-MEDEL BASCONES, Derechos Humanos y Libertades en la Europa Comunitaria, Madrid: Sociedad Española para los Derechos Humanos, 1992, p.43.

${ }^{35} \mathrm{Tal}$ y como Carrillo Salcedo destaca, el que el CEDH "sea una fuente de inspiración del TJCE no significa que esté jurídicamente vinculado". Cfr. J.A. CARRILlo SAlCEDo, "La Protección de los Derechos Humanos en las Comunidades Europeas". Op. cit; p.21.

${ }^{36}$ Conclusiones del Abogado General Antonio La Pergola presentadas en el asunto 299/95, caso Kremzow, Rec. p.I-2631.

${ }^{37}$ Sentencias TJCE de 18 de junio de 1991, asunto 260/89, caso ERT, Rec.; p.I-2925 (ECLI:EU:C:1991:254); y de 29 de mayo de 1997, asunto 299/95, caso Kremzow, Rec.; p.I-2637(ECLI:EU:C:1997:254), entre otras.

${ }^{38}$ L. López Guerra, "El Tribunal Europeo de Derechos Humanos, el Tribunal de Justicia de la UE y "Le Mouvement Nécessaire des choses",Teoría y Realidad Constitucional, núm. 39, 2017, pp. 163-188

${ }^{39}$ Sentencias del TJCE de 12 de noviembre de 1969, asunto 29/69, caso Stauder, Rec. 196900419 (ECLI:EU:C:1969:57), p.425; y de 17 de julio de 1997, asuntos acumulados 248/95 y 249/95, caso SAM, Rec. p.I-43 (ECLI:EU:C:1997:377), de 28 de abril de 1998, asunto 200/96, caso Metronome, Rec.p.I-1953 (ECLI:EU:C:1998:172), "según reiterada jurisprudencia, el derecho de propiedad forma parte de los principios generales del Derecho comunitario". 
nacional únicamente puede afectar a sus propias competencias (del TJUE) si se cumplen los requisitos esenciales para la preservación de la naturaleza de éstas y, por lo tanto, no se pone en peligro la autonomía del sistema jurídico comunitario". Y aún más claramente, en el apartado 186 se lee que las apreciaciones del TJUE "relativas al ámbito de aplicación material del Derecho de la Unión, especialmente a efectos de determinar si un Estado miembro está obligado a respetar los derechos fundamentales de la Unión, no deberían poder ser cuestionadas por el TEDH".

102. En síntesis, "un acuerdo internacional no puede vulnerar el orden de competencias fijado por los Tratados ni, por lo tanto, la autonomía del sistema jurídico comunitario" (aparatado 201 del Dictamen 2/13).

103. Es decir, que pese al "diálogo" y recepción de la jurisprudencia del TEDH por parte del TJUE, sería contrario al Derecho de la UE que el TEDH primara sobre el TJUE.

104. Efecto obvio e inherente a la no adhesión de la UE al CEDH es que éste último no forma parte de las fuentes del Derecho de la Unión.

\section{La Cuestión prejudicial Florescu}

105. La STJUE de 13.6.2017,-258/14 (Florescu) es la primera y, de momento, única sentencia en la que el TJUE ha invocado la jurisprudencia del TEDH sobre el derecho a prestaciones sociales como derecho de propiedad.

\section{A) La reforma de pensiones en Rumanía como respuesta a la Crisis}

106. El litigio trae causa de la reforma legislativa llevada a cabo en Rumanía por la ley 329/2009, consistente en la prohibición de acumular una pensión neta del sector público con los ingresos obtenidos de actividades ejercidas en el seno de instituciones públicas.

107. Como expresamente indica el artículo 2 de la ley 329/2009 "las medidas que ésta establece tienen un carácter excepcional y están destinadas a reducir los efectos de la crisis económica y a dar cumplimiento a las obligaciones derivadas del Memorando de Acuerdo y del Acuerdo de derechos de giro celebrado entre Rumanía y la Comisión y el FMI".

108. Tal y como reconoció el Abogado General Bot en sus conclusiones presentadas el 21.12.2016, "el Memorando de Acuerdo es un acto adoptado por las instituciones. En efecto, éste ha sido adoptado sobre la base del artículo 143 TFUE". Y "corresponde a las autoridades rumanas aplicar las medidas que estimen adecuadas y necesarias para cumplir los objetivos generales definidos en el Memorando de Acuerdo, y éste no impone la adopción de una normativa nacional, como la considerada en el litigio principal".

109. Para el Abogado General "en el contexto muy particular de la crisis económica a la que se enfrentan los Estados miembros, estos, así como las instituciones de la Unión, son ciertamente los que mejor pueden determinar qué medidas pueden tener mayor impacto para sanear el gasto público. Así pues, pienso que los Estados miembros disponen de una amplia facultad discrecional en la materia".

110. Es decir, la crisis económica y financiera mundial vendría a ser la justificación, en última instancia, de las reformas impulsadas a nivel nacional para cumplir compromisos derivados del Derecho de la UE. Pero, sin duda, esta política de austeridad tiene un elevado coste social, como reconoce el Parlamento Europeo en su Resolución de 14.6.2017:"los recortes y la congelación de las pensiones incrementan el riesgo de pobreza en la vejez". 


\section{B) Sobre la vulneración del artículo 17 de la Carta de los Derechos Fundamentales de la Unión Europea}

111. En otro orden de ideas es digno de resaltar el hecho de que en la cuestión prejudicial Florescu no se invoque como infringido el artículo 34 de la Carta de los Derechos Fundamentales de la UE que proclama el derecho a la Seguridad Social, sino su artículo 17 que dice:

112. "Toda persona tiene derecho a disfrutar de la propiedad de los bienes que haya adquirido legalmente, a usarlos, a disponer de ellos y a legarlos. Nadie puede ser privado de su propiedad más que por causa de utilidad pública, en los casos y condiciones previstos en la ley y a cambio, en un tiempo razonable, de una justa indemnización por su pérdida. El uso de los bienes podrá regularse por ley en la medida en que resulte necesario para el interés general".

113. Como señala la STJUE de 13.6.2017, para determinar el alcance del derecho fundamental al respeto de la propiedad, es preciso tener en cuenta, a la luz del artículo 52.3 de la Carta, el artículo primero del Primer Protocolo Adicional al CEDH. Por ello, el TJUE con cita de la jurisprudencia del TEDH concluye que "cuando una normativa establece el pago automático de una prestación social, engendra, para quienes reúnen sus requisitos, un interés patrimonial que entra en el ámbito de aplicación del artículo 1 del Protocolo Adicional y por lo tanto, los derechos derivados del pago de cotizaciones a un régimen de seguridad social constituyen derechos patrimoniales a efectos de este artículo".

114. Por lo que se refiere al artículo 17 de la Carta, en el asunto Florescu el TJUE afirma que "la jurisprudencia consolidada del Tribunal de Justicia se desprende que el derecho de propiedad garantizado por ese artículo no tiene carácter absoluto y que su ejercicio puede ser objeto de restricciones justificadas por objetivos de interés general perseguidos por la Unión". Además, la medida nacional controvertida tiene carácter excepcional y temporal, "y no conlleva una privación pura y simple del derecho a la pensión de las personas que se encuentran en la situación de los recurrentes en el litigio principal, dado que estos pueden continuar percibiendo su pensión de jubilación si renuncian a ejercer paralelamente una actividad profesional remunerada en el seno de una institución pública”.

115. Por todo lo cual el TJUE concluye que "la normativa nacional considerada en el litigio principal es adecuada para conseguir el objetivo de interés general perseguido y es necesaria para alcanzarlo".

\section{El primer protocolo adicional del Convenio Europeo de Derechos Humanos, ¿Canon herme- néutico para interpelar el Derecho a prestaciones sociales en España?}

\section{El artículo 10.2 CE}

116. Por mandato del artículo 10.2 de nuestra Constitución los derechos fundamentales y las libertades constitucionalmente reconocidas se interpretarán conforme a la Declaración Universal de Derechos Humanos y a los Tratados y Acuerdos Internacionales ratificados por España en estas materias.

117. En relación con la exégesis del artículo 10.2 CE la primera incógnita que se suscita es si la remisión a los Tratados Internacionales se circunscribiría al Convenio Europeo de Derechos Humanos o se extiende también a sus Protocolos Adicionales y a la jurisprudencia del TEDH.

118. La primera cuestión podemos resolverla con base a la sentencia del Tribunal Constitucional 89/1995, de 6 de junio, de la que claramente se deduce que los derechos y libertades constitucionales han de interpretarse de conformidad con los Protocolos del CEDH, al menos aquéllos que tienen carácter sustantivo. Y entre estos últimos se encuentra el Primer Protocolo Adicional ${ }^{40}$.

\footnotetext{
${ }^{40}$ Cfr.J.A. Carrillo Salcedo, "El Convenio Europeo de Derechos Humanos y sus Protocolos Adicionales", en: Consejo
} 
119. Asimismo, la doctrina ${ }^{41}$ se ha decantado mayoritariamente por una interpretación teleológica del precepto, omnicomprensiva tanto del propio Convenio como de la jurisprudencia del TEDH ${ }^{42}$. Y, de hecho, no sólo es frecuente que en las Sentencias del TC se citen sentencia del TEDH sino que, tajantemente, la STC 303/1993, de 25 de octubre, afirma que la jurisprudencia del TEDH "resulta de aplicación inmediata en nuestro ordenamiento en virtud de lo dispuesto en el artículo 10.2 CE".

\section{A) Sobre el alcance del concepto de Derechos fundamentales a los efectos del artículo $10.2 \mathrm{CE}$}

120. Otra cuestión en modo alguno desprovista de interés que plantea el artículo $10.2 \mathrm{CE}$ es la de determinar cuáles sean los derechos fundamentales y libertades ${ }^{43}$ que hayan de interpretarse de conformidad con las normas internacionales en la materia ratificadas por España.

121. A efectos puramente polemizadores, diversas interpretaciones resultarían plausibles:

122. La opción más restrictiva sería la que identificara los "derechos fundamentales y libertades" a los que alude el artículo 10.2 CE con la sección primera del capítulo segundo del Título I de la CE (artículos 15-29), que lleva por rúbrica, precisamente, "de los derechos fundamentales y de las libertades públicas".

123. Pero cabría, asimismo, defender que la obligación que impone el artículo 10.2 a los poderes públicos abarca sólo a los derechos y libertades fundamentales que gozan de la protección reforzada prevista en el artículo 53.2 CE y que pueden ser objeto de tutela a través del recurso de amparo.

124. Una tercera solución sería la postulada por CRUZ VILLALON" ${ }^{44}$, quien propuso "llamar derechos fundamentales, básicamente, como criterio general, a los contenidos en todo el capítulo segundo, sin hacer distinción entre las dos secciones de este capítulo. Aunque sin extender el concepto al capítulo tercero, dedicado a la versión nacional de los derechos sociales". Opinión igualmente defendida por otros autores ${ }^{45}$.

125. Una cuarta tesis, más expansiva, consideraría que la eficacia del artículo 10.2 se extendería a todos los derechos y libertades consagrados en el Título Primero de la Constitución ${ }^{46}$. Desde este

General del Poder Judicial, Cuadernos de Derecho Judicial. Jurisprudencia del Tribunal Europeo de Derechos Humanos II, Madrid, 1995, p.21.

${ }^{41}$ Entre otros muchos, A. Poyal Costa, "La Protección de los Derechos Fundamentales en el Derecho Comunitario", Revista de estudios europeos, $n^{\circ}$ 8, 1994, p.97. YA. SALADo OsunA, "Efectos y Ejecución de las Sentencias del Tribunal Europeo de Derechos Humanos en Derecho Español", en AA.VV., Derecho Constitucional para el Siglo XXI: actas del VIII Congreso Iberoamericano de Derecho Constitucional, Vol.1, p. 195.

Por su parte, L.M. Bujosa VAdell, Las Sentencias del Tribunal Europeo de Derechos Humanos y el Ordenamiento Español, Tecnos, Madrid, 1997, p.67; llega a afirmar que "a través de esta norma se produce una constitucionalización de la interpretación que se deriva de las normas internacionales sobre derechos humanos ratificadas por nuestro país.

${ }^{42}$ Por contra, ver F. Rey Martínez; "El Derecho de Propiedad Privada en el Derecho Europeo". Op. cit; p.65:"el TJCE aunque se ha referido explícitamente a la CEDH como criterio de interpretación de los principios generales comunitarios en relación a los derechos fundamentales, no ha tenido en cuenta explícitamente la jurisprudencia del TEDH, lo cual significa no aplicar el derecho viviente".

${ }^{43}$ G. Cámara Villar,Votos Particulares y Derechos Fundamentales en la Práctica del Tribunal Constitucional Español, Ministerio de Justicia, Madrid, 1993, pp.76-77:"ni existen derechos humanos como realidades ópticas, ni existe tampoco un concepto doctrinal y dogmático universalmente válido de derechofundamental".

Ante semejantes dificultades, no falta quién opte por emplear de"modo casi indistinto los términos de derechos fundamentales, derechos humanos y libertades públicas". Cfr. José Manuel Romero Moreno,Proceso y Derechos Fundamentales en la España del Siglo XIX, Centro de Estudios Constitucionales, Madrid, 1983, p.11.

${ }^{44}$ P. Cruz Villalón, en: J.M Sauca (Ed.), Problemas Actuales de los Derechos Fundamentales, Boletín Oficial del Estado, 1994, p.160.

${ }^{4}$ J.J GonzÁlez Rivas,Estudio-Comentario Jurisprudencial de la Protección Constitucional de los Derechos Fundamentales, Ed. Comares, Granada, 1992, p.123.

${ }^{46}$ E.García de Enterría,E. Linde yL.I.Ortega, El Sistema Europeo de Protección de los Derechos Humanos, Ed. Civitas, Madrid, 1979, p.181.

A.E PÉrez LuÑo,Derechos Humanos, Estado de Derecho y Constitución, Tecnos, Madrid, 1984, pp.418-421. 
prisma la referencia del artículo 10.2 CE a los "derechos fundamentales y a las libertades que la Constitución reconoce" no se limitaría al Capítulo II o a la Sección Primera de ese mismo capítulo, sino que comprendería a todo el Título Primero, pues de no haber sido tal la intención del constituyente lo habría "señalado de forma explícita y directa" $"$.

126. Y por último, pero no por ello menos sugerente, partiendo de la premisa de que "la sistemática de la CE conoce algún fallo, pues alguno de los derechos fundamentales se han regulado en otros Títulos de la misma (artículos 105.a, 105.b, 106.2, 121, 125)" "48, podría incluso postularse que la obligación que impone el artículo 10.2 CE se extendería a todos y cada uno de los derechos y libertades contemplados por la Constitución ${ }^{49}$, independientemente de su ubicación en la Carta Magna ${ }^{50}$. En apoyo de esta tesis podría citarse la sentencia $146 / 1986^{51}$ que para interpretar el concepto de Asistencia Social (art. 148.1.20 CE) se remite a los instrumentos internacionales ratificados por España.

127. Opiniones tan dispares, podrían, quizás, armonizarse de admitir que la expresión "derechos fundamentales" no tiene una acepción unívoca, sino que está dotada de distinto alcance según se tratara de la aplicación del artículo 10.2 CE (concepto amplio), o de la aplicación de preceptos tales como los artículos 53.1, 53.2 y $81 \mathrm{CE}$ (concepto restrictivo).

128. En todo caso, y parafraseando a $S O L O Z A B A L^{52}$ cabría concluir que "los derechos fundamentales se protegen por su importancia, pero obviamente, no deben su importancia a su protección".

\section{B) Las prestaciones sociales como Derecho de propiedad ¿Derecho fundamental?}

129. El derecho de propiedad ha estado presente en todas las Constituciones españolas: desde la Constitución de Cádiz de 1812 (artículo 4) hasta la vigente Constitución de 1978 (artículo 33).

130. A los efectos de valorar los efectos de la jurisprudencia del TEDH en materia de prestaciones sociales como derecho de propiedad en España resulta necesario despejar la incógnita de si el derecho de propiedad per se puede reputarse como "derecho fundamental".

131. Por la ubicación del artículo 33 en el texto constitucional, no resultaría defendible que estemos ante un derecho "fundamental" a los efectos de los artículos 53.2 y $81 \mathrm{CE}^{53}$.

L. López Guerra, E. Espín, J. García Morillo, P. Pérez Tremps y M. Satrústegui,Derecho Constitucional, Tirant lo Blanch, 2016, p.106:"este Título I representa, pues, la declaración de derechos del ordenamiento español por cuanto en él, siguiendo la tradición constitucional, se enumeran los derechos fundamentales. Estos toman su denominación de "fundamentales" de la importancia que poseen dentro del ordenamiento como elemento básico para configurar el sistema jurídico y político."

${ }^{47}$ B. DE CAStro Cid, Los Derechos Económicos, Sociales y Culturales. Análisis a la luz de la Teoría General de los Derechos Humanos, Secretariado de Publicaciones de la Universidad de León, Ponferrada, 1993; pp.189-191.

48 J. de Esteban y P. J. GonZÁlez-Trevijano, Curso de Derecho Constitucional Español, Universidad Complutense de Madrid, 1992, p.269.

${ }^{49}$ Sentencia del TC 37/1988 de 3 de marzo (ECLI:ES:TC:1988:37):"este Tribunal, cuya jurisprudencia ha estado siempre orientada por el principio de que los textos constitucionales que reconocen derechos fundamentales no contienen palabras vanas, sino garantías jurídicas inviolables por los Poderes Públicos".

${ }^{50}$ G. Cámara Villar,Votos Particulares y Derechos Fundamentales en la Práctica del Tribunal Constitucional Español, Op. Cit, p.78:"tanto el encabezamiento general del Título I, como el del Capítulo IV tienen un significado de amplia y genérica referencia al conjunto del sistema constitucional de los derechos. Y lo mismo podría decirse de las expresiones en el artículo 10.2, 27.2 y 94.1 CE.".

En el mismo sentido, J. de Esteban y P. J. González-Trevijano, Curso de Derecho Constitucional Español,Op. Cit, p.271:"de forma lógica habría que mantener, de acuerdo con el enunciado del Capítulo Cuarto del Título I, que, de forma general, el artículo 53 considera igualmente derechos fundamentales a los comprendidos tanto en el Capítulo Segundo como en el Tercero. Dicho de otra forma, serían así derechos fundamentales todos los regulados en la Norma Fundamental".

${ }^{51}$ STC 146/1986, de 25 de noviembre (ECLI:ES:TC:1986:146).

${ }^{52}$ Citado por G. CÁmara Villar,Votos Particulares y Derechos Fundamentales en la Práctica del Tribunal Constitucional Español, Op. Cit, p.83.

${ }^{53}$ El derecho de propiedad, aisladamente, no es susceptible de amparo ni de protección reforzada. Por todos, J.J. GonZÁLeZ Rivas,Estudio-Comentario Jurisprudencial de la Protección Constitucional de los Derechos Fundamentales, Op. Cit, p.116. 
132. Pero, en cambio, a los efectos hermenéuticos del artículo $10.2 \mathrm{CE}$, parece razonable defender el carácter de "fundamental" del derecho de propiedad ${ }^{54}$, en el sentido de que el mismo habrá de ser interpretado conforme a los instrumentos ratificados por España, tales como la Declaración Universal de Derechos Humanos ${ }^{55}$, el $\mathrm{CEDH}^{56}$ y sus Protocolos. Pues España, al ratificar instrumentos internacionales sobre protección de Derechos Humanos queda obligada no sólo a garantizar el respeto de los mismos en el territorio nacional, sino también a interpretar su "positivación constitucional" de conformidad con dichos textos internacionales, ya que una solución distinta los vaciaría de "efecto útil".

133. Similares razonamientos conducirían a defender que la obligación que impone el artículo 10.2 CE ha de extenderse también a otros derechos consagrados en el Capítulo III del Título I de la CE en la medida que son proclamados como derechos fundamentales por instrumentos internacionales incorporados al ordenamiento interno. Este sería, el caso, del Derecho a la Seguridad Social, regulado en el artículo 41de nuestra Constitución.

134. Por tanto, siendo incuestionable que el derecho de propiedad es un derecho fundamental para el Primer Protocolo Adicional al CEDH, el derecho a prestaciones sociales -como derecho de propiedad- se ha de interpretar a la luz de la jurisprudencia del TEDH sobre el mismo.

\section{Las prestaciones sociales, ¿Derecho de propiedad para el Tribunal Constitucional?}

135. Aunque "el Derecho a la Seguridad Social no puede construirse sobre la inseguridad jurídica" ${ }^{57}$, tradicionalmente se ha venido rechazando la aplicación del principio de "la confianza legítima" al ámbito de la protección social ${ }^{58}$.

136. Resulta paradigmático el criterio sentado por el Tribunal Constitucional ${ }^{59}$ a propósito del anticipo de la edad de jubilación de los funcionarios de 70 a 65 años, en el que se decantó por negar la existencia de derechos adquiridos expropiados por la legislación impugnada ${ }^{60}$.

${ }^{54}$ M. López-Medel Bascones, Derechos Humanos y Libertades en la Europa Comunitaria, Op. Cit, p.28:"el artículo 1 del Protocolo Adicional de 1952 se corresponde con el artículo 33 de la Constitución".

${ }^{55}$ F. Rey Martínez, "El Derecho de Propiedad Privada en el Derecho Europeo", Op. Cit, p.53:"el art. 17 de la Declaración Universal de Derechos Humanos afirma que toda persona, individual o colectivamente, tiene un derecho a la propiedad. Nadie puede ser arbitrariamente privado de su propiedad. Esta fórmula explicita una declaración enfática de la propiedad como un derecho humano".

${ }^{56}$ El CEDH no extiende su ámbito de aplicación a todos los derechos sociales. Al respecto, J.M. MoreniLla Rodríguez, "Naturaleza del CEDH y Ámbito de las Obligaciones de los Estados en la Jurisprudencia del TEDH" en: Consejo General del Poder Judicial, Cuadernos de Derecho Judicial. Jurisprudencia del Tribunal Europeo de Derechos Humanos II, Madrid, 1995, p.114.

${ }^{57}$ C. Molina Navarrete, "La Tutela de la Confianza Legítima como Principio de Ordenación Jurídica de las Pensiones Públicas" en: Ministerio de Trabajo y Asuntos Sociales, Pensiones Sociales. Problemas y Alternativas, Parte I. Colección Seguridad Social $\mathrm{n}^{\circ}$ 18. Madrid. 1999; p.289.

${ }^{58}$ Sentencia del TC 65/1987, de 21 de mayo de 1987(ECLI:ES:TC:1987:65) :(FJ.19):"yendo más allá del ámbito la certeza respecto al contenido del mandato legal, tampoco puede apreciarse que en lo relativo al presente precepto, se haya visto defraudada la confianza que legítimamente los ciudadanos hubieran depositado en los poderes públicos".

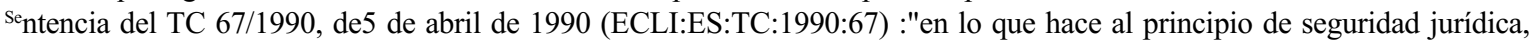
entendida su vulneración como incertidumbre o inseguridad ante lo que se afirma previamente como derecho consolidado o adquirido, ha de precisarse, y según lo expuesto en las sentencias TC 99/1987 de 11 de junio y 178/1989 de 2 de noviembre, que no cabe hablar de tales derechos adquiridos, sino de una situación de beneficio o ventaja que se ha disfrutado por el funcionario y en cuyo mantenimiento invariable no se estima razonable que tuviese derecho a confiar".

59 Sentencias del TC 108/1986, de 29 de julio (ECLI:ES:TC:1986:108); 70/1988, de 19 de abril (ECLI:ES:TC:1988:70); y 99/1987, de 11 de junio(ECLI:TC:1987:99), entre otras.

${ }^{60}$ En el mismo sentido se pronuncia la sentencia del TC 65/1987, de 21 de mayo (ECLI:ES:TC:1987:65):"tanto las aportaciones de los afiliados, como las prestaciones a dispensar, sus niveles y condiciones, vienen determinados por reglas que se integran en el ordenamiento jurídico y que están sujetas a las modificaciones que el legislador introduzca". 
137. Asimismo, la Sentencia $65 / 1990^{61}$ afirma que "el derecho a una pensión no debe confundirse con el derecho a que la regulación legal de su percepción pueda ser lícitamente alterada por el legislador...idénticas consideraciones llevan a excluir también la duda sobre la vulneración del principio de interdicción de la retroactividad y del derecho a no ser privado de derechos sin indemnización, pues, no existe tal derecho".

138. Tesis que no se ha visto alterada con la STC 45/2018, de 26.4.2018, pues si bien en la misma se afirma que la pensión se incorporó al patrimonio jurídico de su titular como el derecho a obtener del Estado una prestación económica periódica de carácter vitalicio y se declara inconstitucional la norma impugnada, no hay ninguna referencia en dicha sentencia al Convenio Europeo de Derechos Humanos ni a sus Protocolos y el fallo del Tribunal se explica en que el procedimiento para suprimir el derecho a pensión omitió las garantías que el Derecho administrativo concede a los administrados.

139. Por tanto, actualmente una diferencia capital entre la jurisprudencia española y la del Tribunal Europeo de Derechos Humanos es la distinta tesis que mantienen sobre si las expectativas de Derecho en el ámbito de la protección social son tutelables e indemnizables.

140. Para nuestro Tribunal Constitucional, "la eficacia y protección del derecho individual -nazca de una relación pública o de una privada- dependerá de su naturaleza y de su asunción más o menos plena por el sujeto, de su ingreso en el patrimonio del individuo, de manera que la irretroactividad sólo es aplicable a los derechos consolidados, asumidos e integrados en el patrimonio del sujeto y no a los pendientes, futuros, condicionados y expectativas" ${ }^{2}$.

141. Sistemáticamente, el Tribunal Constitucional niega que los efectos de reformas en materia de pensiones que afectan a situaciones de hecho surgidas tras la entrada en vigor de la nueva normativa sean indemnizables pues se rechaza que los ciudadanos tuvieran un derecho consolidado a jubilarse a una determinada edad, o a que sus pensiones se revaloricen conforme a la diferencia entre el IPC real y el IPC estimado (STC 49/2015, de 5.3.2015). El Tribunal Constitucional falla sistemáticamente que estamos ante meras expectativas de derecho no indemnizables porque "sólo son expropiables y, por tanto indemnizables la privación de bienes y derechos o incluso intereses patrimoniales legítimos aun no garantizados como derechos subjetivos (por ejemplo, las situaciones en precario). Más aún, la doctrina jurídica y la jurisprudencia consideran, casi unánimemente, que sólo son indemnizables las privaciones de derechos ciertos, efectivos y actuales, pero no eventuales o futuros".

142. Cabe deducir, por tanto, que el derecho a la propiedad privada, que la CE configura como "un haz de facultades individuales sobre las cosas"63, no comprendería dentro de su ámbito de aplicación material a las prestaciones sociales, que a lo sumo han sido calificadas como "bienes jurídicos constitucionalmente tutelados" ${ }^{\prime 6}$.

\section{Conclusiones}

143. Es competencia exclusiva de los Estados legislar en materia de Seguridad Social.

144. El artículo 1 del Primer Protocolo Adicional, que proclama el Derecho de propiedad, en modo impone restricción alguna a la libertad de los Estados contratantes para decidir instaurar, o no, un

\footnotetext{
${ }^{61}$ Sentencia del TC 65/1990, de 5 de abril (ECLI:ES:TC:1990:65):"ni puede hablarse en este supuesto de expropiación o confiscación de derechos patrimoniales, ni puede mantenerse tampoco que esta regulación del legislador, que suprime el disfrute de aquel beneficio o ventaja, cause desigualdad alguna".

${ }^{62}$ SSTC 99/1987, de 11 de junio (ECLI:ES:TC:1987:99); 178/1989, de 2 de noviembre (ECLI:ES:TC:1989:178); y 112/2006, de 5 de abril (ECLI:ES:TC:2006:112).

${ }^{63}$ STC 37/1987, de 26 de marzo (ECLI:ES:TC:1987:37).

${ }^{64}$ STC 126/1994, de 25 de abril (ECLI:ES:TC:1994:126).
} 
régimen de protección social. O para escoger el importe de las prestaciones que se pretende conceder en virtud de tal régimen.

145. A los efectos del TEDH el concepto de propiedad tiene un alcance autónomo frente a los ordenamientos nacionales y no se limita a la propiedad de los bienes físicos.

146. La competencia nacional en materia de Seguridad Social no implica, automáticamente, que resulten conformes al Primer Protocolo Adicional del CEDH todo tipo de reformas legislativas por parte de los Estados dirigida a reducir el gasto social. Prueba de ello son las sentencias Bélané y Baczúr en las que el TEDH concluyó que las reformas legislativas húngaras basadas en una política de austeridad presupuestaria infringían el artículo primero del Primer Protocolo Adicional al Convenio Europeo de Derechos Humanos.

147. En 2018 se ha admitido a trámite una demanda contra España basada en el Primer Protocolo Adicional en donde se cuestiona si la reforma llevada a cabo por la Ley 23/2013, de 23 de diciembre, reguladora del Factor de Sostenibilidad y del Índice de Revalorización del Sistema de Pensiones de la Seguridad Social vulnera el derecho de propiedad de los pensionistas al conllevar una pérdida del poder adquisitivo de los mismos. Dicha reforma se enmarcó dentro de la política de austeridad del Gobierno español para cumplir los compromisos sobre déficit públicos derivados de su condición de Estado miembro de la UE.

148. Ateniéndonos al artículo 10.2 de la Constitución, el derecho a prestaciones sociales ha de ser interpretado en España a la luz de la jurisprudencia del TEDH. Sin embargo, hasta la fecha, nuestro Tribunal Constitucional ha negado que las reformas restrictivas de derechos en el ámbito de las prestaciones sociales sean indemnizables porque parte de la premisa que en estos supuestos sólo existe una expectativa de derecho no indemnizable. Es evidente que existe una discrepancia al respecto entre el TEDH y el Tribunal Constitucional. 